Int. J. Electrochem. Sci., 13 (2018) 6436 - 6450

International Journal of

ELECTROCHEMICAL

SCIENCE

www.electrochemsci.org

\title{
Corrosion Behavior of X70 and X80 Pipeline Steels in Simulated Soil Solution
}

\author{
Xinhua Wang, Xuting Song, Yingchun Chen", Zuquan Wang, Liuwei Zhang \\ College of Mechanical Engineering and Applied Electronics Technology, Beijing University of \\ Technology, Beijing 100124, China \\ *E-mail: ychen08089@163.com
}

doi: $10.20964 / 2018.07 .12$

Received: 9 March 2018 / Accepted: 21 April 2018 / Published: 5 June 2018

Corrosion behavior of X70 and X80 steel in simulated soil solution with AC interference was studied by applied open circuit potential, polarization curve, scanning electron microscope and gravimetry. The corrosion potential of X70 and X80 steel shifted negatively with increasing AC density. Polarization curves were all in active dissolution zone without passivation area. At the low AC density $\left(0-100 \mathrm{~A} / \mathrm{m}^{2}\right)$, the corrosion rate of X70 steel increased rapidly with the density increase, while the change of corrosion rate of X70 steel was not as obvious at high AC density (100-300 A/m²). Under the AC interference with density of $0-300 \mathrm{~A} / \mathrm{m}^{2}$, the corrosion rate of X80 steel increased steadily with the increase of AC density. At the same AC density, the corrosion rate of X70 steel was about 2 times higher than that of X80 steel. At the low AC density, the surface morphology of the corroded X70 showed uniform corrosion: the sample surface was relatively smooth. At the high AC density, more numerous and larger corrosion pits were observed. When AC density was 0-200 A/m $\mathrm{m}^{2}$, the corrosion morphology of X80 steel was uniform with the smooth surface, only with some pitting corrosion at $300 \mathrm{~A} / \mathrm{m}^{2}$ AC density. Thus, corrosion resistance of X80 steel was better than that of X70 steel in simulated soil solutions.

Keywords: X70 steel, X80 steel, alternating current, corrosion rate

\section{FULL TEXT}

(C) 2018 The Authors. Published by ESG (www.electrochemsci.org). This article is an open access article distributed under the terms and conditions of the Creative Commons Attribution license (http://creativecommons.org/licenses/by/4.0/). 